\title{
Tone-Burst ve Klik Uyarılı İşitsel Beyin Sapı Yanıtları ile İşitsel Uyarılmış Durgun Durum Yanıtları Sonuçlarının Karşılaştırılması
}

\author{
A Comparison of the Results Measured by Audotory Steady State Responses and Using \\ Frrequency-Spesific Evoked Auditory Brainstem Response \\ Hüseyin ÖZTARAKÇI ${ }^{1}$, Saime SAĞIROĞLU ${ }^{2}$, Mehmet Akif KILIÇ³
}

${ }^{1}$ Uzm. Dr. Kahramanmaraş Necip Fazıl Şehir Hastanesi Kulak Burun Boğaz Baş ve Boyun Cerrahisi Bölümü, KAHRAMANMARAŞ
${ }^{2}$ Dr. Öğr. Üy. Kahramanmaraş Sütçü İmam Üniversitesi Tip Fakültesi Kulak Burun Boğaz Hastalıkları Anabilim Dalı, KAHRAMANMARAŞ
${ }^{3}$ Prof Dr. İstanbul Medeniyet Üniversitesi Tıp Fakültesi Kulak Burun Boğaz Hastalıkları Anabilim Dalı, İSTANBUL

\section{Öz}

Amaç: Bu çalışmada, ileri-çok ileri derecede sensörinöral işitme kaybı olan hastalarda, tone-burst ve klik İşitsel Beyin Sapı (ABR) ile İşitsel Uyarılmış Durgun Durum (ASSR) sonuçlarını karşılaştırdık.

Gereç ve Yöntemler: Yaşları 2 ay ile 53 yıl arasında değişen, ileri-çok ileri derecede sensörinöral işitme kaybı olan, 30 kişilik hasta grubunun toplam 60 kulağı çalışmaya alındı. Hastalara timpanogram ve akustik refleks ölçümü, otoakustik emisyon, tone-burst ABR, Klik $A B R$ ve ASSR testleri yapildı.

Bulgular: Tone-burst ABR ve ASSR eşikleri arasında iyi bir korelasyon olduğu gözlendi. Spearman korelasyon katsayıları 500; 1000; 2000 ve $4000 \mathrm{~Hz}$ 'ler için sırasıyla $0.612 ; 0.563$; 0.564 ve 0.548 olarak bulundu $(\mathrm{p}<0.01)$.

Sonuç: ASSR, frekans spesifik ölçüm yapabilen otomatik saf ses odyogram eğrisi oluşturarak işitme seviyesini gösteren, çok kısa sürede objektif sonuç verebilen bir ölçüm yöntemidir. Ayrıca, toneburst ve klik ABR ile ASSR gibi tüm testlerin birlikte kullanılması önerilir.

Anahtar Kelimeler: İşitme kaybı, İşitsel beyin sapı yanıtları, İşitsel uyarılmış durgun durum yanıtları, Otoakustik emisyon.

\section{GİRIŞ}

ABR (İşitsel Beyinsapı Cevabı) testinin temeli, ses dalgalarının iç kulakta ve işitme yollarında oluşturduğu aksiyon potansiyeline dayanır. İşitme yollarında oluşan aksiyon potansiyelleri EEG (elektroenselogram) yöntemiyle kaydedilebilir. ABR testinde klik ve tone-burst başta olmak üzere çeşitli uyaranlar kullanılabilir. Bu uyaranların frekans özgüllügüü değişiklik gösterir. Klik ABR’yle elde edilen yanıtlar kokleadaki bütün frekansları içermekle birlikte daha çok 2 ila $4 \mathrm{kHz}$ bölgeleriyle uyumludur. Bu nedenle, klik uyaranla yapılan ABR testi düşük frekans alanlarıyla ilgili sınırlı bilgi verir $(1,2)$. Dolayısıyla klik ABR'yle elde edilen işitme eşikleri tüm frekansları kapsamadığından işitme eşiği eğrisini doğru bir şekilde yansıtmaz. İşitme kaybı konfigürasyonunun doğru olarak elde edilmesi işitme kaybının rehabilitasyonu açısından son derece önemlidir. Bu da frekansa özgü uyaran kullanmak suretiyle frekansa özgü yanıt elde edilmesiyle mümkündür. Frekans özgüllüğünü artırmak için, filtre edilmiș veya çentikli gürültülerle karıştırılmış klik uyaranlar, tone-pip uyaranlar ve

\section{Abstract}

Objective: In this study, we compared the results of Auditory Brainstem Responses (tone-burst and klik ABR) and Auditory Aware Static State Responses (ASSR) in patients with sensorineural hearing loss at advanced and very advanced.

Material and Methods: A total of 60 ears of a 30-patient group with sensorineural hearing loss between 2 months and 53 years of age were included in the study. Patient's tympanogram and acoustic reflex measurement, otoacoustic emission, tone-burst ABR and ASSR tests were performed.

Results: There was a good correlation between tone-burst ABR and ASSR thresholds. Spearman's correlation coefficients were found 500; 1000; 2000 and $4000 \mathrm{~Hz} ; 0.612,0.563 ; 0.564$ and 0.548 respectively $(\mathrm{p}<0.01)$.

Conclusion: ASSR is a measurement method which can produce a frequency specific measurement, which gives better results at high frequencies, produces a pure sound audiogram curve shows hearing level and it is an objective measurement method which give results in a very short time. Additionaly, we recommended use combination of all tests such as tone-burst ABR and ASSR.

Key Words: Hearing loss, Auditory brainstem responses, Auditory aware static state responses, Otoacoustic emission.

tone-burst uyaranlar kullanılmaktadır. Bunların içinde en sık kullanılan tone-burst uyaranlardır.

Frekansa özgü yanıt elde etmek amacıyla, uyarılmış işitsel potasiyel ölçüm yöntemlerinde başka çeşitli uyaranlar da geliştirilmiştir. Kuwada ve ark. tarafından 1986 yılında tarif edilen, amplitüt ve/veya frekans modülasyonu yoluyla frekans özgüllüğü artırılmış sinüzoidal uyaranlarla ölçüm yapılan ASSR (İşitsel Uyarılmış Durgun Durum Yanıtları) yönteminde de frekansa özgü yanıt elde edilebilir (3). ASSR, temel olarak EEG dalgaları ve işitsel uyarılar arasındaki bağlantıya dayanarak ölçüm yapan bir yöntemdir. ASSR, amplitüdü ve frekansı module edilmiș devamlı saf ses uyaran verilerek $250-8000 \mathrm{~Hz}$ arasında frekans spesifik ölçüm yapabilen, otomatik saf ses odyogram eğrisi oluşturarak işitme seviyesini gösteren objektif bir yöntemdir. Son zamanlarda kullanımı yaygınlaşan ASSR yönteminde aynı anda birden fazla frekans için eşik araştırması yapilabilmektedir.

İletişim: $\begin{aligned} & \text { Dr. Saime Sağıroğlu, KSÜ Tip Fakültesi Kulak Burun } \\ & \text { Boğaz Hastalıkları AD, Kahramanmaraş }\end{aligned}$
DOI:
$\quad \mathbf{1 0 . 1 7 5 1 7 / k s u t f d . 4 1 9 0 9 9}$


Bu çalışmada, tone-burst ABR ile ASSR testleri arasındaki uyumu ortaya koymak amacıyla ileri-çok ileri derecede sensörinöral işitme kaybı olan hastalarda elde ettiğimiz sonuçları karşılaştırdık.

\section{GEREÇ VE YÖNTEM}

Odyolojik değerlendirme, Kulak Burun Boğaz Hastalıkları Anabilim Dalı Odyoloji Laboratuvarında, yaşları 2 ay ile 53 yl arasında değişen, ileri-çok ileri derecede sensörinöral işitme kaybı olan, 30 kişilik hasta grubunun toplam 60 kulağında yapıldı. Çalışmaya alınan bütün hastaların otoskopik muayeneleri normal olarak değerlendirildi. Muayene sonrası bütün hastalara Interacustics Impedans Audiometer (AZ 26) cihazı ile timpanogram ve akustik refleks ölçümü, Otodynamics DP Echoport cihazı ile otoakustik emisyon (geçici uyarılmış (TEOAE) ve distorsiyon ürünü (DPOAE) otoakustik emisyon cevapları) testleri yapıldı. Daha sonraki bir seansta Navigator PRO cihazı (Bio-logic Inc, Mundelein, IL, ABD) ile AEP ve MASTER programları kullanılarak klik ABR, 500; 1000; 2000 ve $4000 \mathrm{~Hz}$ 'lerde tone-burst $A B R$ ve ASSR eşikleri ölçüldü. Kayıt sırasında tüm olgularda sedasyon uygulandı. Hastalara sedasyon sağlamak amacıyla öncelikli olarak $2 \mathrm{mg} / \mathrm{kg}$ oral hidroksizin verildi. Bu şekilde fizyolojik uyku sağlanamayan hastalara daha sonraki seansta $0,1 \mathrm{mg} / \mathrm{kg}$ intranazal midazolam verildi. Midazolamla da başarısız olunan olgulara bir sonraki seansta genel anestezi uyguland. Elektrot empedanslarının $5 \mathrm{~K} \Omega$ 'un altına olmasına dikkat edildi (tüm kayıtlarımızda elektrot empedansı $1 \mathrm{~K} \Omega$ 'du).

Klik ve tone-burst $\mathrm{ABR}$ ölçümleri için AEP programı kullanıld. Her iki testte de uyaran alternan polariteli olacak şekilde ayarlandı. Öncelikle klik ABR testiyle hastaların işitme eşikleri belirlendi. Daha sonra sırasıyla tone-burst ABR ve ASSR testleri yapıldı. Hastalarımızın işitme kaybı ileri-çok ileri derecede olduğundan, teste genellikle cihazın maksimum çıkış düzeyinde uyaran kullanılarak başlandı. (Tablo 1). Bu düzeyde yanıt alınan olgularda $10 \mathrm{~dB}$ nHL'lik basamaklar halinde düşülerek tone-burst $A B R$ eşikleri araştırıldı. Hiç yanıt alınamaması durumunda cihazın maksimum çıkış düzeyi o frekans için eşik seviyesi olarak kabul edildi.

ASSR ölçümleri için MASTER programı kullanıldı. İleri derecede işitme kaybı olan hastalarda, dikotik multipl frekans tekniğiyle her iki kulağa da eş zamanlı uyaran verilerek 0.5; 1;2

Tablo 1. Tone-burst ABR ölçüm tekniği

\begin{tabular}{|l|l|}
\hline Uyaran & Tone-burst \\
\hline Pencereleme & Blackman \\
\hline Uyaran oranı & $27,7 / \mathrm{s}$ \\
\hline Maskeleme & Yok \\
\hline Polarite & Bütün frekanslarda alternan \\
\hline Çevirici & Insert earphones \\
\hline Filtreleme & $30-1500 \mathrm{~Hz}$ \\
\hline Averajlama & 2000 \\
\hline Elektrot yerleşimi & $\begin{array}{l}\text { Her iki mastoit bölge ve alnın üst } \\
\text { bölgesi }\end{array}$ \\
\hline $\begin{array}{l}\text { Maksimum uyaran } \\
\text { șiddeti }\end{array}$ & $\begin{array}{l}500 \mathrm{~Hz} \text { te } 95 \mathrm{~dB} \mathrm{nHL} \\
1000 \mathrm{~Hz} \text { te } 105 \mathrm{~dB} \mathrm{nHL} \\
2000 \mathrm{~Hz} \text { te } 105 \mathrm{~dB} \mathrm{nHL} \\
4000 \mathrm{~Hz} \text { te } 100 \mathrm{~dB} \mathrm{nHL}\end{array}$ \\
\hline \hline
\end{tabular}

KSU Medical Journal 2018;13(3) 68-71 ve $4 \mathrm{kHz}$ lerde ölçüm yapıldd. Çok ileri derecede işitme kayıplı hastalarda ise multipl frekans ASSR tekniğinde cihazın maksimum çıkış seviyesinin sınırlı (80 dB HL $\leq$ şiddet düzeyi) olmasından dolayı tek frekans ASSR tekniği kullanıldı. Her iki kulağa eş zamanlı olarak tekli frekans verilerek ölçüm yapıldı. AM/FM modülasyon frekansı tüm frekanslarda sol kulak için $67 \mathrm{~Hz}$, sağ kulak için $69 \mathrm{~Hz}$ olacak șekilde uygulandı. Çoklu frekans ASSR tekniğinde ise $0.5 ; 1 ; 2$ ve 4 kHz'te sağ kulak için sirasıly 82; 84; 87 ve $89 \mathrm{~Hz}$, sol kulak için sırasıyla 91; 94; 96 ve $99 \mathrm{~Hz}$ MF kullanıldı (Tablo 2). Çevirici (transducer) olarak Bio-logic insert earphones kullanıld.

\section{Tablo 2: ASSR ölçüm tekniği}

\begin{tabular}{|l|l|}
\hline $\begin{array}{l}\text { Uyaran veri- } \\
\text { liş şekli }\end{array}$ & Dikotik, tekli veya çoklu frekans \\
\hline Modülasyon & AM2 ve FM \\
\hline $\begin{array}{l}\text { AM/FM } \\
\text { modülasyon } \\
\text { oranı }\end{array}$ & $\begin{array}{l}\text { Tek frekans ASSR tekniğinde; sol kulak için } \\
67 \mathrm{~Hz} \text {, sağ kulak için } 69 \mathrm{~Hz} \\
\text { Çoklu frekans ASSR tekniğinde sırasıyla } \\
0,5 ; 1 ; 2 \text { ve } 4 \text { kHz'lerde sağ kulak için 82; } \\
84 ; 87 \text { ve } 89 \mathrm{~Hz} \text {, sol kulak için 91; 94; } 96 \text { ve } \\
99 \mathrm{~Hz}\end{array}$ \\
\hline Çevirici & Insert earphones \\
\hline Yanıt analizi & F testi \\
\hline $\begin{array}{l}\text { Maksimum } \\
\text { uyaran şid- } \\
\text { deti }\end{array}$ & $\begin{array}{l}500 \mathrm{~Hz} \text { te } 115 \mathrm{~dB} \mathrm{HL} \\
1000 \mathrm{~Hz} \text { te } 120 \mathrm{~dB} \mathrm{HL}\end{array}$ \\
& $2000 \mathrm{~Hz}$ te $115 \mathrm{~dB} \mathrm{HL}$ \\
& $4000 \mathrm{~Hz}$ te $115 \mathrm{~dB} \mathrm{HL}$ \\
\hline
\end{tabular}

Cihazın maksimum çıkışı 500; 2000 ve $4000 \mathrm{~Hz}$ için 115 dB HL, $1000 \mathrm{~Hz}$ için $120 \mathrm{~dB}$ HL idi. Çok ileri derecede işitme kayıplı hastalarda teste bu seviyelerden başlanıp, $10 \mathrm{~dB}$ HL düşülerek eşik seviyesi araştırıldı. Klik ve tone-burst ABR testlerinde olduğu gibi hiçbir yanıt alınamayan ölçümlerde cihazın maksimum ses şiddeti çıkış düzeyi eşik olarak kabul edildi. Yanıtın varlığ $\mathrm{F}$ testi yoluyla araştırıldı

İstatiksel Analiz

İstatistiksel analizler SPSS 13.0 (SPSS Inc, Chicago,IL USA) bilgisayar programıla yapıldı. Verilerin analizinde Spearman korelasyon testi kullanıldı. P değerinin 0.01 'in altındaki sonuçlar istatistiksel olarak anlamlı kabul edildi. Klik ABR, dört frekansta (500; 1000; 2000 ve $4000 \mathrm{~Hz}$ ) ölçülen tone-burst ABR ve ASSR eşikleri arasındaki korelasyon Spearman korelasyon katsayısı ( $\mathrm{r}$ değeri) hesaplanarak saptand1.

\section{BULGULAR}

Tone-burst ABR ve ASSR eşikleri arasında iyi bir korelasyon olduğu gözlendi. Spearman korelasyon katsayıları 500; 1000; 2000 ve $4000 \mathrm{~Hz}$ 'ler için sirasiyla 0.612; 0.563 ; 0.564 ve 0.548 olarak bulundu $(\mathrm{p}<0.01)$. Klik ABR ile tüm frekanslardaki tone-burst ABR arasındaki korelasyon çok iyi derecedeydi. Klik ABR ile dört frekanstaki ASSR eşikleri arasındaki korelasyon ise iyi derecedeydi (Tablo 3 ).

Toplam 30 hastanın altmış kulağında yapılan ölçümlerde yanıt alınamaması durumunda cihazın maksimum çıkış düzeyi eşik değeri olarak kabul edildi. Elde edilen eşik değeri ortalamaları ve standart sapmaları Tablo 4’te görülmektedir. 
Tablo 3: Klik ABR, tone-burst ABR ve ASSR eşikleri arasındaki korelasyon katsayıları

\begin{tabular}{|l|l|l|l|l|l|}
\hline Uyaran & ASSR $\mathbf{( 5 0 0 ~ H z )}$ & ASSR $(\mathbf{1 0 0 0} \mathbf{~ H z})$ & ASSR $\mathbf{( 2 0 0 0 ~ H z )}$ & ASSR $\mathbf{( 4 0 0 0 ~ H z )}$ & Klik \\
\hline $\begin{array}{l}\text { Tone-burst } \\
\mathbf{5 0 0} \mathbf{~ H z})\end{array}$ & 0.612 & 0.614 & 0.708 & 0.658 & 0.999 \\
\hline $\begin{array}{l}\text { Tone-burst } \\
(\mathbf{1 0 0 0} \mathbf{~ H z})\end{array}$ & 0.628 & 0.563 & 0.612 & 0.560 & 0.907 \\
\hline $\begin{array}{l}\text { Tone-burst } \\
(\mathbf{2 0 0 0} \mathbf{~ H z})\end{array}$ & 0.557 & 0.562 & 0.564 & 0.588 & 0.875 \\
\hline $\begin{array}{l}\text { Tone-burst } \\
(\mathbf{4 0 0 0} \mathbf{H z})\end{array}$ & 0.486 & 0.556 & 0.601 & 0.548 & 0.910 \\
\hline Klik & 0.612 & 0.614 & 0.706 & 0.658 & 1.000 \\
\hline
\end{tabular}

Tablo 4: Testlerde elde edilen eşik değerlerinin ortalamaları ve standart sapmaları (birim: klik ve tone-burst $A B R$ için $d B$ $n H L, A S S R$ için $d B H L)$

\begin{tabular}{|l|l|l|l|}
\hline & Ortalama & $\begin{array}{l}\text { Alt ve üst } \\
\text { sinırlar }\end{array}$ & $\begin{array}{l}\text { Standart } \\
\text { sapma }\end{array}$ \\
\hline $\begin{array}{l}\text { Tone-burst } \\
\text { ABR }(500 \\
\text { Hz) }\end{array}$ & 92 & $70-95$ & 7.9 \\
\hline $\begin{array}{l}\text { Tone-burst } \\
\text { ABR }(1000 \\
\text { Hz })\end{array}$ & 100 & $70-105$ & 12.1 \\
\hline $\begin{array}{l}\text { Tone-burst } \\
\text { ABR }(2000 \\
\text { Hz })\end{array}$ & 102 & $70-105$ & 9.3 \\
\hline $\begin{array}{l}\text { Tone-burst } \\
\text { ABR }(4000 \\
\text { Hz })\end{array}$ & 97 & $60-100$ & 8.8 \\
\hline $\begin{array}{l}\text { ASSR } \\
(500 \mathrm{~Hz})\end{array}$ & 107 & $80-115$ & 12.2 \\
\hline $\begin{array}{l}\text { ASSR } \\
(1000 \mathrm{~Hz})\end{array}$ & 110 & $70-120$ & 13.9 \\
\hline $\begin{array}{l}\text { ASSR } \\
(2000 \mathrm{~Hz})\end{array}$ & 109 & $80-115$ & 11.6 \\
\hline $\begin{array}{l}\text { ASSR } \\
(4000 \mathrm{~Hz})\end{array}$ & 109 & $70-115$ & 11.6 \\
\hline Klik ABR & 92 & $70-95$ & 8.9 \\
\hline
\end{tabular}

Tablo 4: Testlerde elde edilen eşik değerlerinin ortalamaları ve standart sapmaları (birim: klik ve tone-burst $A B R$ için $\mathrm{dB}$ nHL, ASSR için dB HL)

\section{TARTIŞMA}

İşitme kayıplarında, tone-burst ABR veya ASSR testi gibi yöntemler kullanılarak frekansa özgü eșik belirlenebilmektedir. $\mathrm{Bu}$ çalışmada, tüm frekanslarda tone-burst ABR eşikleriyle klik ABR eşikleri arasında çok iyi derecede, tüm frekanslarda ASSR ile klik ABR arasında iyi derecede ve tüm frekanslarda tone-burst ABR eşikleriyle yine tüm frekanslarda ASSR eşikleri arasında iyi derecede bir korelasyon olduğunu göstermektedir.

Klasik yöntemlerle işitmesi değerlendirilemeyen hastalar içerisinde en önemli grubu yenidoğanlar ve küçük çocuklar oluşturmaktadır. $\mathrm{Bu}$ yaş grubundaki işitme kayıplarının rehabilitasyonunda erken müdahale çok önemlidir. Dil gelişiminin başarılı bir şekilde tamamlanması işitme fonksiyonunun yeterli olmasına bağlıdır. Normal gelişim gösteren bir bebekte işitme yollarının matürasyonu ilk 4 ay içinde tamamlanır ve takip eden aylarda dil yeteneği gelişmeye başlar $(4,5)$. Bu nedenle işitme durumunun ilk 6 ay içinde doğru bir şekilde değerlendirilmesi önemlidir. İşitme kayıplı çocuklarda işitme kaybı tipinin, derecesinin ve konfigürasyonunun belirlenmesi büyük önem taşır (6). Bu da ancak, işitme eşiklerinin frekansa özgü olarak elde edilmesiyle sağlanabilir (7).

Tone-burst ABR'nin, tipik olarak 10-20 dB'de eşik tahmininde doğruluğa sahip olduğu gösterilmiştir $(8,9,10)$. $\mathrm{Bu}$ testlerde doğruluk oranı, beşinci dalganın varlığını veya yokluğunu görsel olarak denetleyen ve öznel olarak yargılayan odyoloğun bilgi ve deneyimlerine bağlıdır. Bununla birlikte, ASSR testinin doğruluğu, klinisyeni tamamen tatmin etmez ve işitme kaybı derecesine göre değişir. Çok frekanslı ASSR testi, 500 ila $4000 \mathrm{~Hz}$ arasında değişen taşıyıcı frekanslar 10-25 $\mathrm{dB}$ için tipiktir. Ancak normal işitme sınırları olan ve düşük derecede işitme kayıpları olan kişiler için verdiği bilgi zayıftır $(11,12,13)$.

Yapılan çalışmalarda 2000-4000 Hz de klik ABR ile ASSR arasında kuvvetli korelasyon bulunmuş, alçak frekanslardaki ileri derecedeki işitme kayıplarında klik ABR ile saptanamayan işitme eşiklerinin ASSR ile saptandığı gösterilmiştir $(14,15)$. Ayrıca yapılan bu çalışmada, ABR’nin en iyi saptayabildiği işitme eşik seviyesi $90 \mathrm{~dB}$, ASSR'nin en iyi saptayabildiği eşik seviyeyi $105 \mathrm{~dB}$ olarak saptamışlardır.

Özellikle işitme kayıplı hastalarda, ASSR ve toneburst ABR eşiklerini karşılaştıran çalışma sayısı sınırlıdır. Johnson ve Brown (16), işitme kayıplı erişkinlerde tone-burst ABR eşikleriyle ASSR eşiklerini karşılaştırmış, 500; 1000 ve $2000 \mathrm{~Hz}$ 'lerde tone-burst ABR ve ASSR eşikleri arasında çok iyi derecede korelasyon elde ettiklerini bildirmişlerdir. Aoyagi ve ark. (17)'nın, 3-15 yaş arasındaki 125 çocuk üzerinde yaptığı çalışmada; 1000 Hz’te ASSR, tone-burst ABR ve davranış odyometrisi eşiklerini karşılaştırmışlar, ASSR eşikleriyle davranışsal eşikler arasındaki korelasyonu, toneburst ABR'yle davranışsal eşikler arasındaki korelasyondan yüksek bulmuşlardır. Kosmider (18) Standart ABR ile ASSR nin $2000-4000 \mathrm{~Hz}$ frekans aralığında uyumlu sonuçlar verdiği ancak standart ABR nin alçak frekanslarda eşik tayininde yetersiz kaldığı bildirmişlerdir. Çalışmamızda, ASSR ve toneburst ABR testlerinde elde edilen eşik düzeyleri arasında orta derecede bir korelasyon olduğunu gözledik. Her iki test arasındaki korelasyonun çok iyi derecede olması gerekirken testlerin maksimum çıkışlarının farklı olması ve yanıt 
alınamayan hastalarda eşik değeri olarak maksimum çıkış gücünün alınması nedeniyle korelasyonun beklenenden daha düşük çıkmasına yol açtığını düşünüyoruz.

İşitme engelli çocuklarda uygulanan rehabilitasyon çalıșmasının bașarılı olması için ișitme kaybı konfigürasyonunun doğru bir şekilde belirlenmesi gerekir. Tone-burst ABR'de maksimum şiddet çıkışı sinırlı olduğu için çok ileri derecede işitme kaybında rezidüel işitme varlığ araştırılamaz, bu hastalarda ASSR testi çok daha yararlıdır.

\section{SONUÇ}

İşitme kayıplarının düzeyini ve konfigürasyonunu ortaya koymak için odyolojik testlerin hiç biri tek başına kullanılmamalıdır. Tüm odyolojik testler bir batarya oluşturur, birinin eksiğini diğeri tamamlar. Bu nedenle mümkünse toneburst ABR ve ASSR gibi bütün testler bir arada yapılmalıdır. Frekansa özgü bilgi elde ederken test süresini kısaltmak da amaçlanıyorsa, ileri ve çok ileri derecedeki işitme kayıplarında ASSR, daha az düzeydeki işitme kayıplarında tone-burst ABR tercih edilmelidir.

\section{KAYNAKLAR}

1. Stapells DR, Picton TW, Durieux-Smith A. Principles and applications in audiotory evoked potentials. In: Jacobson JT, eds. Electrophysiologic measures of frequency-specific auditory function. Allyn \& Bacon; 1994. p. 251-283.

2. Brookhouser PE, Gorga MP, Kelly WJ. Auditory brainstem response results as predictors of behavioral auditory thresholds in severe and profound hearing impairment. Laryngoscope 1990; 10: 803-10.

3. Kuwada S, Batra R, Maher VL. Scalp potentials of normal and hearing-impaired subjects in response to sinusoidally amplitude-modulated tones. Hear Res 1986; 21: 179-192.

4. Lins OG, Picton TW, Boucher BL, Durieux-Smith A, Champagne SC, Moran LM, et al. Frequency- specific audiometry using steady state responses. Ear \& Hearing. 1996; 17: 81-96.

5. LJ Hood. Clinical Applications of the Auditory Brainstem Response, Singular Publishing Group Inc., San Diego, London, 1998; pp. 112-142.

6. Hofmann M, Wouters J. Electrically Evoked Auditory Steady State Responses in Cochlear Implant Users. J Assoc Res Otolaryngol. 2010; 11: 267-282.

7. Foster M, Stevens J, Brennan S. Intra and intersubject variability in auditory steady-state response amplitude with high modulation rates to $1000 \mathrm{~Hz}$ amplitude modulated and tone pip stimuli. Int J Audiol. 2013; 52: 507-12.

8. Luts H, Desloovere C, Kumar A, Vandermeersch E, Wouters J. Objective assesment of frequency-specific hearing threshold in babies. Int J Pediatric Otorhinolaryngol 2004; 68: 915-926.

9. Vander Werff KR, Brown CJ, Gienapp BA, Schmidt Clay KM. Comparison of auditory steady-state response and auditory brainstem response threshols in children. J Am Acad Audiol 2002; 13: 227-235.

10. Johnson TA, Brown CJ. Threshold prediction using the auditory steady-state response and the tone burst auditory brain stem response: a within-subject comparison. Ear Hear. 2005; 26: 559-76.

11. Aoyagi M, Suzuki Y, Yokota M, Furuse H, Watanabe T, Ito T. Reliability of $80-\mathrm{Hz}$ amplitude-modulation-following response detected by phase coherence. Audiology \& Neurootology, 1999; 4: 28-37.

12. Kosmider D. Auditory brainstem response and the steadystate evoked potential as predictors of the behavioral audiogram. Unpublished master's thesis. The University of Melbourne, Department of Otolaryngology, Audiology and Speech Sciences 1997. 